Review

\title{
Swine Dysentery: Aetiology, Pathogenicity, Determinants of Transmission and the Fight against the Disease
}

\author{
Avelino Alvarez-Ordóñez *, Francisco Javier Martínez-Lobo, Héctor Arguello, Ana Carvajal \\ and Pedro Rubio \\ Infectious Diseases and Epidemiology Unit, University of León, León 24071, Spain; \\ E-Mails: fmarl@unileon.es (F.J.M.-L.); hector.arguello@unileon.es (H.A.); \\ ana.carvajal@unileon.es (A.C.); p.rubio@unileon.es (P.R.) \\ * Author to whom correspondence should be addressed; E-Mail: aalvo@unileon.es; \\ Tel.: +34-987-291-306.
}

Received: 18 March 2013; in revised form: 22 April 2013 / Accepted: 23 April 2013 / Published: 10 May 2013

\begin{abstract}
Swine Dysentery (SD) is a severe mucohaemorhagic enteric disease of pigs caused by Brachyspira hyodysenteriae, which has a large impact on pig production and causes important losses due to mortality and sub-optimal performance. Although $B$. hyodysenteriae has been traditionally considered a pathogen mainly transmitted by direct contact, through the introduction of subclinically infected animals into a previously uninfected herd, recent findings position $B$. hyodysenteriae as a potential threat for indirect transmission between farms. This article summarizes the knowledge available on the etiological agent of SD and its virulence traits, and reviews the determinants of SD transmission. The between-herds and within-herd transmission routes are addressed. The factors affecting disease transmission are thoroughly discussed, i.e., environmental survival of the pathogen, husbandry factors (production system, production stage, farm management), role of vectors, diet influence and interaction of the microorganism with gut microbiota. Finally, prophylactic and therapeutic approaches to fight against the disease are briefly described.
\end{abstract}

Keywords: swine dysentery; Brachyspira hyodysenteriae; transmission; control 


\section{Introduction}

Swine Dysentery (SD) is a severe mucohaemorhagic enteric disease of pigs which has a large impact on pig production, with important losses caused by mortality and sub-optimal performance with reduced feed conversion and gain weight indexes [1]. SD was first described in 1921 [2], but the aetiology was not determined until the seventies, when Brachyspira hyodysenteriae was confirmed as the causative agent $[3,4]$. SD primarily affects pigs during the growth and finishing periods, and clinical signs, which range from mild, mucous diarrhoea with unaltered general condition to severe haemorhagic diarrhoea with a mortality rate of 50-90\% [5], seem to occur in a cyclic manner at 3 to 4 weeks intervals, with these recurring symptoms often appearing only after removal of therapeutic antibiotics [6].

SD is a widely distributed disease around the World, although studies regarding epidemiology are scarce and the reported prevalence significantly varies among them. Thus, $B$. hyodysenteriae reported prevalence ranges from $0 \%$ to near $40 \%$ [6-10]. Variations in prevalence can be due to the use of different diagnostic methods or to differences among countries in housing, management, feeding regimes, etc. $[11,12]$. Moreover, whereas in many countries the prevalence may be concealed by the use of antimicrobials as feed additives, in others the ban of antibiotics as growth promoters may have resulted in an increase in SD prevalence [13,14].

It is important to note that recent reports have associated clinical dysentery with infection by strongly beta-hemolytic Brachyspira spp. that are not confirmed as B. hyodysenteriae by PCR and gene sequencing [15,16]. This includes the recently described species Brachyspira hampsonii [17]. Interestingly, reproduction of mucohaemorhagic diarrhoea and colitis indistinguishable from SD has been achieved through experimental inoculation with a $B$. hampsonii strain [18].

B. hyodysenteriae has been traditionally considered a pathogen mainly transmitted by direct contact, through the introduction of subclinically infected animals into a previously uninfected herd [19]. However, recent findings position $B$. hyodysenteriae as a potential threat for indirect transmission between farms, i.e., it can survive for large periods of time in pig faeces, and it has been found in feral pigs, laying chickens, mallards, rheas, seagulls, rodents, dogs, flies and other insects, among others [20-27].

This article summarizes the knowledge available on B. hyodysenteriae, the most well-characterized SD agent, including its virulence traits, and reviews the determinants of SD transmission. The between-herds and within-herd transmission routes are addressed. The factors affecting disease transmission are thoroughly discussed, i.e., environmental survival of the pathogen, husbandry factors (production system, production stage, farm management), role of vectors, diet influence and interaction of the microorganism with gut microbiota. Finally, prophylactic and therapeutic approaches to fight against the disease are briefly described.

\section{The Etiological Agent: General Considerations and Virulence Traits; Lessons from the Genome}

B. hyodysenteriae is a Gram negative, motile, helically coiled (spiral-shaped), anaerobic bacterium which belongs to the Brachyspiraceae Family (Phylum Spirochaetes) [28]. B. hyodysenteriae is associated with mucus in the lumen and crypts of the porcine caecum and colon, where it causes damage to enterocytes. The lack of genetic tools, and the difficulties involved in its genetic manipulation have hindered the identification of virulence factors and metabolic traits allowing the 
microorganism to successfully colonize the porcine intestinal tract [29]. However, the first representative genome of a $B$. hyodysenteriae strain (B. hyodysenteriae strain WA1), determined in 2009 by Bellgard and colleagues, has shed light on the main adaptations of the species to its lifestyle in the porcine large intestine [30]. In that study, B. hyodysenteriae was shown to differ from all the other spirochaetes, including Leptospira, Borrelia and Treponema, in signal transduction and in amino acid transport and metabolism systems. A relative paucity of signal transduction mechanisms relative to the genome size, which probably reflects the relatively narrow ecological niche occupied by the microorganism in the porcine large intestine, was observed. On the other hand, the proportion of genes involved in amino acid transport and metabolism was relatively high, and this probably reflects the adaptation to the environment of the intestinal tract, where proteins from host cells and dietary ingredients are abundant. It was also noteworthy the high proportion of putative protein-coding sequences (CDS) showing high similarity to proteins from the genus Escherichia and Clostridium. It is likely that these genes were involved in horizontal gene transfer events involving $B$. hyodysenteriae and one or more Clostridium and Escherichia species. Since they inhabit the same environment in the large intestine, opportunities for gene exchange favouring their survival in this niche are abundant. Several CDS predicted as putative virulence factors were identified. These included proteases involved in virulence via the destruction of host tissues, and ankyrin proteins, known to bind to the host chromatin playing a critical role in the interaction with the host cells. Moreover, seven potential hemolysin production genes, ten flagella-associated genes that can form part of a type III secretory system, at least 84 putative genes associated with chemotaxis and motility, and the key genes necessary for lipooligosaccharide biosynthesis were identified and proposed as virulence factors. In agreement, other studies had previously highlighted the role played by hemolysins, flagella, the lipooligosaccharide and bacterial chemotaxis and motility in SD pathogenesis [31-34]. Other authors have also identified various virulence life-style factors (e.g., outer membrane proteins, NADH oxidase, proteins of iron metabolism) with a predicted role in B. hyodysenteriae pathogenicity [35,36]. The presence of a 35,940 bp circular plasmid in B. hyodysenteriae strain WA1 was also confirmed by Bellgard and co-workers [30]. Interestingly, a recent study by La and colleagues [37] has found evidence that this plasmid contributes to B. hyodysenteriae virulence. These authors have shown that the WA1 plasmid contains genes encoding enzymes forming part of the rhamnose biosynthesis pathway ( $r f b$ genes) that are predicted to function in incorporation of rhamnose in the O-antigen backbone of the cell wall lipooligosaccharide. In addition, other glycosyltransferases were shown to be encoded by the plasmid, and these may be involved in incorporating other sugars into the lipooligosaccharide.

\section{Environmental Determinants of SD Transmission}

Although SD is a multifactorial disease which pathogenesis is complex and poorly understood, several factors have been associated with the occurrence of the condition. Thus, the outcome of infection by $B$. hyodysenteriae might be influenced by age [38], stress [39], acid secretion in the stomach [40], differences in the dose of the infectious agent, diet and the virulence of B. hyodysenteriae strains [41,42]. The following sections of the review emphasize the main environmental factors determining disease establishment and transmission, i.e., environmental survival of the pathogen, husbandry factors, role of vectors, relevance of pig's diet, and interaction of the microorganism with gut microbiota (Figure 1). 
Figure 1. Factors influencing the establishment and transmission of Swine Dysentery (SD). The determinant factor of the disease is the pathogen Brachyspira hyodisenteriae whose persistence in the environment is enhanced by low temperatures and the presence of faeces. Factors which promote the transmission, establishment and persistence of the disease are the presence of vectors, diets with high energy and proteins, and bad husbandry practices; the role of highly fermentable diets is unclear. In contrast, all-in/all-out (AI/AO) management together with cleaning and disinfection, strict biosecurity and highly digestible diets are preventive factors to the establishment of SD. Finally, the production system is a decisive factor to a great extent in the control and prevention of the disease. Farrow-to-finish herds have lower risk of SD entrance but in contrast the persistence of the pathogen is higher than in multi-site production systems.

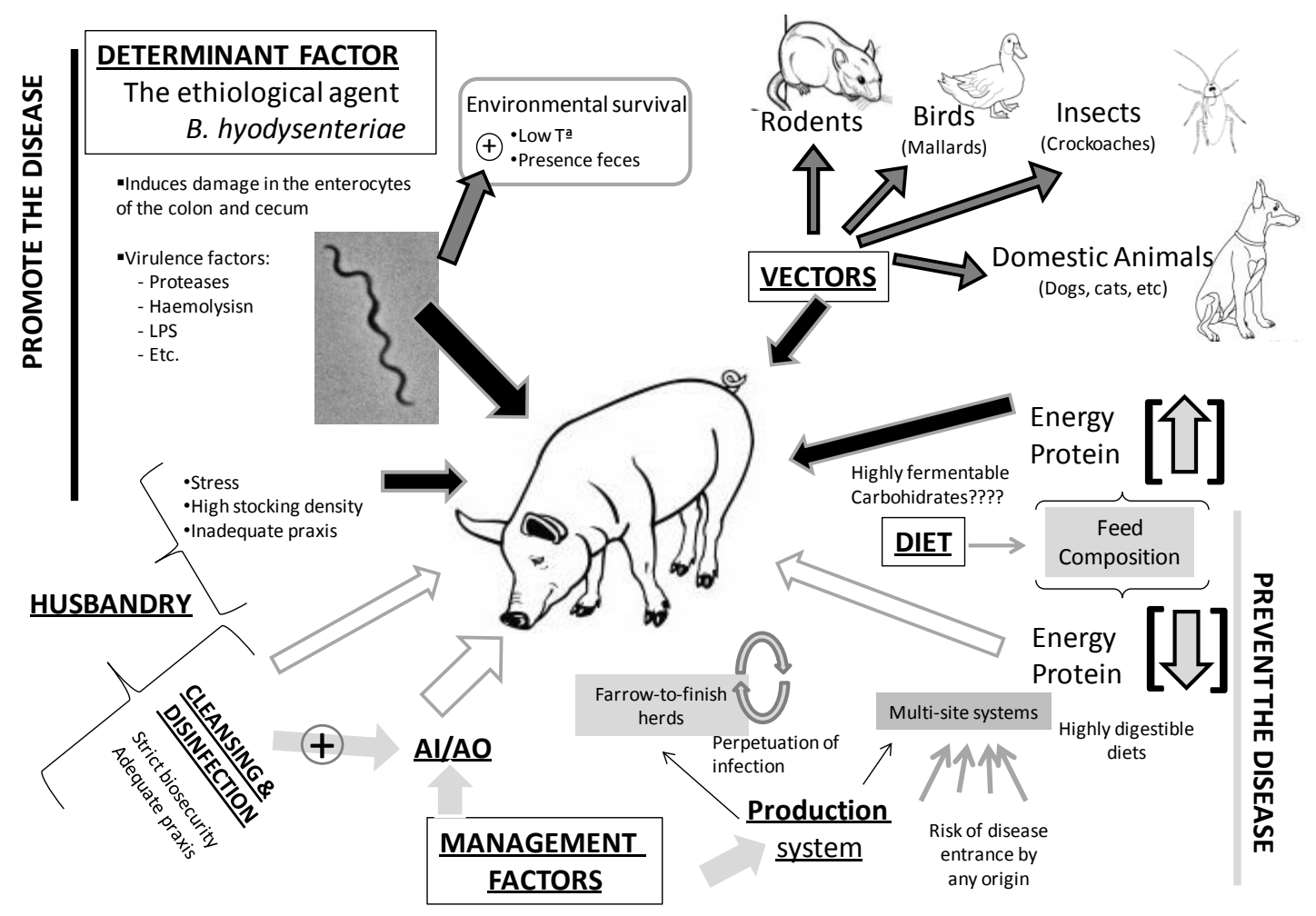

\subsection{Environmental Survival}

Although $B$. hyodysenteriae is an anaerobic pathogen, it is able to survive in the environment of the farm for considerable periods of time, depending on the presence of organic matter and the environmental temperature $[22,43,44]$. B. hyodysenteriae is relatively resistant in the environment of a pig house. It can survive in soil held at $10{ }^{\circ} \mathrm{C}$ during 10 days. In the presence of faeces, the survival time is increased to 78 days, and even can reach 112 days in pure pig faeces [22]. Also Chia and Taylor [43] showed that $B$. hyodysenteriae was able to survive for 48 days in dysenteric faeces held between 0 and $10{ }^{\circ} \mathrm{C}$, although it only survived for 7 days at $25{ }^{\circ} \mathrm{C}$, and for less than $24 \mathrm{~h}$ at $37{ }^{\circ} \mathrm{C}$. Compared to other spirochaetes, its environmental survival capability is shorter; for instance, B. pilosicoli, the agent of the porcine intestinal spirochaetosis, survived for 119 days in pure soil, and 210 days both in soil with $10 \%$ pig faeces and in pure pig faeces [22]. 


\subsection{Biosecurity and Husbandry Factors}

Apart from the etiological agent, other factors also play an important role in the success of the establishment or persistence of the disease. This section of the review deals with handling and biosecurity aspects of SD.

The production system is a decisive factor to a great extent in the control and prevention of the disease. In farrow-to-finish herds (including farrow-to-weaners and farrow-to-growers piggeries), the pathogen can persist in endemic infected sows, which have overcome the infection and developed protective immunity but still shed the pathogen in their faeces. The proximity of facilities and continuous flow of animals in this sort of production system will facilitate the transmission of infection to non-infected animals. On an endemically infected farrow-to-finish piggery transmission of infection to susceptible pigs occurs primarily by contact with faecal material that originates from clinically infected pigs or from asymptomatic carriers colonized by the spirochaete [45]. Depending on the herd immune status and the measures taken to control the disease (based on antimicrobial treatments and vaccination [46,47]), animals will be more or less severely affected and the disease will affect principally pigs at the growing or finishing period when the medication used to control respiratory infections is removed, favouring the expression of SD. In contrast, it is easier to halt the transmission of the pathogen in animals reared in integration systems in which each part of the production is physically independent from the other [48]. However, in integration systems at the growing and finishing stages pigs from different origins are mingled. In consequence these stages constitute a risk if pigs from farms with different status to SD (infected or non-infected) are mixed. Not only productive parameters but also the health status must therefore be considered in the acquisition of pigs. The replacement of breeders with others from the same source each year was shown to be protective against the appearance of the disease [49].

The introduction of all-in/all-out procedures (AIAO) facilitates the disruption of infection transmission among production stages and from consecutive reared batches. The establishment of AIAO requires the cleaning and disinfection of the accommodation together with a period of time during which the barn is empty before it is refilled. Several studies have reported the benefits of using AIAO in SD control. For instance, an increase in the use of antimicrobials to battle SD was registered after the banning of growth promoters in Sweden [50]. However, the introduction of AIAO in Swedish pig production, the closure of many small production units and the increase in size of the remaining herds reversed this situation. Also AIAO management was shown to reduce the odds of being PCR-positive to Brachyspira spp. by 4-fold in a study on spirochaetes in poultry [51]. The key in AIAO procedures is the application of efficient protocols of cleaning and disinfection. Considering the susceptibility of Brachyspira spp. to the most commonly used disinfectants [43,52,53], the proper application of disinfectants should be effective in removing the environmental spirochaetes present in the herd. However, apart from a thorough disinfection of the pens and corridors, the disinfection programme should also be applied to tools and equipment which could be in contact with faeces and therefore harbour the pathogen. Special attention should be paid to the pit, where B. hyodysenteriae can survive for long periods of time. Therefore, manure handling systems must be switched to clean formats [52] by adequate draining, drying and lime applications of manure pits, ponds, etc. Effective 
protocols used $0.15 \mathrm{~kg} / \mathrm{L}$ of hydrated calcium oxide in slurry channels [54] and calcium oxide $2 \mathrm{~kg} / \mathrm{m}^{2}$ poured into the canals [55].

Biosecurity aspects are also important for the prevention of disease transmission. These include general aspects, such as the presence of double fence to prevent the entrance of wild animals, and the inclusion of footbaths at the gates of the farm (vehicles) and at the entrance of the barns (caretakers and visitors). Farms should be designed to facilitate feed distribution and cadaver collection preventing the entrance of vehicles which can disperse pathogens from infected farms. Similarly, the presence of a lockable facility for changing clothes which includes farm clothes and boots for caretakers and also visitors is really recommended. In addition, newly acquired pigs should be kept in quarantine facilities for at least three weeks. This process is strongly recommended since clinical signs usually appear in subclinically infected animals as a result of transportation [52]. In the risk factors study performed by Robertson and colleagues [49] some of the aspects mentioned here, double fence, feed transport or visits to farm, were linked to the prevention or presence of SD at the farm.

Finally, certain husbandry factors associated with pig handling could be a potential trigger or enhancer of SD. Asymptomatic pigs may develop diarrhoea following stressful management procedures, such as transferring to new pens, mixture of animals from different origin, weighting or changes in feed [5]. At the same time, adequate stocking densities and temperatures are also factors that have to be considered.

\subsection{Vectors}

The bacterial genus Brachyspira consists of intestinal spirochaetes with the capability of colonizing a broad spectrum of hosts. Potential reservoirs of infection on a piggery include feral and other animals [19].

Wild rodents are potential vectors of Brachyspira spp. A number of studies have shown that both the brown rat (Rattus norvegicus) and the house mouse (Mus musculus) are susceptible to B. hyodysenteriae infection and have demonstrated the potential transmissibility of the pathogen from mice to pigs [56,57]. Furthermore, typing studies by PFGE have linked strains detected in infected pigs with those isolated from mice and rats from the same farm [58-60].

Other important reservoirs are birds. A number of studies have been focused on the isolation of B. hyodysenteriae and other spirochaetes from birds with the aim of determining if they constitute a source of infection for production animals and humans [21,23,61-66]. Taken together, their results strongly support the conclusion that intestinal spirochaetes are commonly found in the wild-living water-bird species analysed (principally mallards). It is thought that they could play an important role in the transmission of the disease between neighbouring farms and also in the dispersion of the pathogen in their migrations, when the excretion of spirochaetes in faeces is quite frequent [23]. Despite the fact that $B$. hyodysenteriae is frequently isolated from birds the clinical significance of the bacteria in non-porcine species remains somewhat unclear [67-69]. Colonization most likely does not cause clinical disease signs in mallards and some degree of host adaptation occurs according to Jansson and colleagues [65]. It is worth mentioning that experimental challenges carried out with B. hyodysenteriae isolates from birds have failed to infect pigs [23,70].

Some insect species could carry important enteric disease agents with implications for on-farm spread and maintenance, affecting biosecurity and eradication protocols on pig farms. Insect vectors 
seem to harbour Brachyspira spp. and constitute a reservoir and source of infection for pigs [71]. B. hyodysenteriae has been isolated from cockroaches and flies [26]. In the study by Blunt and McOrist [72] five of 14 intestine samples from cockroaches (Blatta orientalis) present in SD infected farms were confirmed positive for B. hyodysenteriae. Moreover, experimental infection of these cockroaches showed that they remained positive for at least three days after inoculation.

Wild boars may also be a potential source of infection. Philips and colleagues [27] could isolate spirochaetes from feral pigs. In contrast, neither B. hyodysenteriae nor any other intestinal spirochaetes were detected in wild boar samples collected in Sweden [73]. Apart from feral animals, domestic animals present in the farms, principally dogs, can be a reservoir of Brachyspira spp. as it has been asserted by several authors [74].

Despite the fact that SD is a host specific disease caused by B. hyodysenteriae in swine, the information provided in this section demonstrates the importance of other animals, including birds, as potential reservoirs and source of infection for susceptible pigs. These vectors must be taken into consideration when control and, above all, eradication programmes are going to be put under way.

\subsection{The Role of Diet and Intestinal Microbiota}

The pig's diet has been proposed as one of the most important factors that can influence on spirochaete colonization and on the occurrence of mucohaemorhagic diarrhoea. Particularly, feed composition and abrupt dietary changes have been associated with an increase in the incidence of SD.

The influence of diet composition on the appearance of SD might be mainly related to the digestibility of their ingredients, which, in turn may have an effect on the composition and equilibrium of the large intestinal microbiota [75,76]. The composition of the microbiota is relevant because B. hyodysenteriae executes its pathogenic action in association with other anaerobic members of the large intestinal microbiota to induce extensive inflammation and necrosis of the epithelial surface of the caecum and colon [5]. In addition, changes in the colonic microbiota could either enhance or inhibit the colonization by $B$. hyodysenteriae. The inhibition could be direct or indirect, by inhibition of any of the synergistic bacteria that have been reported to facilitate colonization of this spirochaete [77]. These effects on spirochaete colonization might be reflected in a severe SD after exposure to B. hyodysenteriae or in a complete prevention of, or at least a decrease in, the clinical signs of the disease. However, the precise mechanisms by which the diet's composition predispose to or protect against SD are not fully understood.

The addition of soybean meal to pig's diet seems to be a very important factor on the appearance of SD. Thus, pigs experimentally fed large quantities of soya showed clinical signs of dysentery [68]. Moreover, it is known that the addition of a high percentage of soybean meal to meal formulation is associated with both small intestine [78] and large intestine diarrhoea [79]. Although the exact mechanism that predisposes to SD is not yet understood, it is likely that the increase in the protein:carbohydrate ratio in the hindgut associated with a high percentage of soya in the meal plays a role through alterations in the colonic microbiota.

On the contrary, highly digestible diets reduce the fermentative activity in the large intestine. This fact might contribute to inhibit the colonization by $B$. hyodysenteriae and consequently to prevent the onset of SD. It has been suggested that clinical protection in pigs fed highly digestible diets is due to 
a reduced fermentation in the large intestine compared to pigs that developed SD [80]. However, protection against SD by feeding pigs with highly digestible diets has not always been achieved [81,82]. Conversely, protection against SD can be achieved with diets supplemented with highly fermentable carbohydrates [83], which produce the opposite effect than highly digestible diets in the hindgut. However, the above mentioned formulation was based on dried chicory roots and sweet lupins, which has allowed speculating with the possibility that the protective effect was due to the presence of inulin in dried chicory roots [84]. Fermentation of inulin by the indigenous microbiota results in the production of volatile fatty acids (VFA) and gases [85], which causes a reduction in luminal $\mathrm{pH}$ values in the caecum, upper colon and lower colon. This decrease in luminal $\mathrm{pH}$ values might prevent colonization by $B$. hyodysentariae [86]. An alternative mechanism of action would be the regulation of metabolic activity by inulin supplementation, decreasing the protein:carbohydrate ratio in the hindgut and, consequently, the protein fermentation in the hindgut. This fact causes an increase in lactate and butyrate-producing bacteria $[87,88]$ and a reduction in proteolytic bacteria, which could be synergistic with $B$. hyodysenteriae in SD pathogenesis.

Altogether, these results indicate that the reproducibility of protection against SD by modifications of the diet is low, pointing towards a complex effect in which the diet formulation, including raw materials used and their proportion, the microbiota composition and other yet unrevealed factors play a role in the final outcome of infection. Besides, the inclusion of theoretically protective raw materials in the diet might be too expensive to be routinely implemented in pig diet formulations. More studies are required to clarify the precise role of the diet in the development of the disease and to find economically viable formulations to prevent the condition.

\section{The Fight against SD}

\subsection{Therapy with Antibiotics}

Treatment of SD involves the use of antibiotics. Pleuromutilins (tiamulin and valnemulin) have been used for this purpose in the European Union (EU) [89]. Tiamulin and valnemulin are semi-synthetic derivatives of the naturally occurring diterpene antibiotic pleuromutilin which show outstanding activity against anaerobic bacteria and are used exclusively in animals, largely in swine. Also macrolides (tylosin and, more recently, tylvalosin) and the closely related lincomycin (lincosamide) have been commonly included in SD therapeutic strategies [5] (Table 1). However, the emergence of B. hyodysenteriae strains with reduced susceptibility to one or more of these antibiotics and the presence of genetically diverse multiresistant isolates has been confirmed in several countries [90-98]. This fact complicates treatment and control of SD and should alert veterinary surgeons and pig farmers for the need of a strategic approach to select antibiotics, which must only be used on strict indications following proper field and laboratory diagnosis in order to guarantee their long-term efficiency for SD treatment. 
Table 1. Main antimicrobials used for the treatment and prevention of swine dysentery (SD).

\begin{tabular}{|c|c|c|c|c|c|}
\hline Drug & $\begin{array}{c}\text { Dosage in } \\
\text { SD treatment }{ }^{\text {a }}\end{array}$ & $\begin{array}{c}\text { Dosage in } \\
\text { SD prevention }\end{array}$ & $\begin{array}{c}\text { Point mutations associated to } \\
\text { decreased susceptibility }\end{array}$ & $\begin{array}{l}\text { Wild type MIC } \\
\text { cutoff values }\end{array}$ & $\begin{array}{l}\text { Clinical MIC } \\
\text { breakpoint }^{\mathrm{d}}\end{array}$ \\
\hline Tiamulin & $\begin{array}{l}\text { Im: } 10 \mathrm{mg} / \mathrm{kg} \text { bw for } 1-3 \text { days } \\
\text { Po: } 8 \mathrm{mg} / \mathrm{kg} \text { bw for } 5-7 \text { days in } \\
\text { drinking water } \\
\text { In feed medication: } 100 \mathrm{ppm} \text { for } \\
7-10 \text { days }\end{array}$ & $\begin{array}{l}\text { In feed medication: } \\
\quad 30-40 \mathrm{ppm}\end{array}$ & $\begin{array}{l}\text { 23S rRNA gene position } 2058 \text { and } 2032 \\
\text { L3 ribosomal protein gene } 148\end{array}$ & $>0.25 \mu \mathrm{g} / \mathrm{mL}$ & $>2 \mu \mathrm{g} / \mathrm{mL}$ \\
\hline Valnemulin & $\begin{array}{l}\text { In feed medication: } 3-4 \mathrm{mg} / \mathrm{kg} \text { bw } \\
\text { for } 1-4 \text { weeks }\end{array}$ & $\begin{array}{l}\text { In feed medication: } \\
25 \mathrm{ppm}\end{array}$ & $\begin{array}{l}\text { 23S rRNA gene position } 2058 \text { and } 2032 \\
\text { L3 ribosomal protein gene position } 149\end{array}$ & $>0.125 \mu \mathrm{g} / \mathrm{mL}$ & $>5 \mu \mathrm{g} / \mathrm{mL}$ \\
\hline Tylosin & $\begin{array}{c}\mathrm{Im}: 10 \mathrm{mg} / \mathrm{kg} \text { bw for } 3-5 \text { days } \\
\text { Po: } 5-10 \mathrm{mg} / \mathrm{kg} \text { bw in drinking } \\
\text { water for } 5-7 \text { days }\end{array}$ & 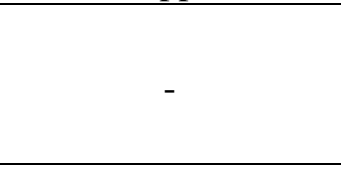 & 23S rRNA gene position 2058 & $>16 \mu \mathrm{g} / \mathrm{mL}$ & $>32 \mu \mathrm{g} / \mathrm{mL}$ \\
\hline Tylvalosin & $\begin{array}{l}\text { In feed medication: } 4.25 \mathrm{mg} / \mathrm{kg} \text { bw } \\
\text { for } 10-14 \text { days }\end{array}$ & $\begin{array}{l}\text { In feed medication: } \\
2.125 \mathrm{mg} / \mathrm{kg} \cdot \mathrm{bw}\end{array}$ & 23S rRNA gene position 2058 and 2059 & $>1 \mu \mathrm{g} / \mathrm{mL}$ & $>32 \mu \mathrm{g} / \mathrm{mL}$ \\
\hline Lincomycin & $\begin{array}{l}\text { Po: } 8 \mathrm{mg} / \mathrm{kg} \text { bw in drinking water } \\
\text { for } 1 \text { to } 10 \text { days } \\
\text { In feed medication: } 100 \mathrm{ppm} \text { until } \\
\text { clinical signs disappear followed } \\
\text { by } 40 \mathrm{ppm}\end{array}$ & $\begin{array}{l}\text { In feed medication: } \\
\qquad 44 \mathrm{ppm}\end{array}$ & $\begin{array}{l}\text { 23S rRNA gene position 2058, } 2059 \\
\text { and } 2032\end{array}$ & $>1 \mu \mathrm{g} / \mathrm{mL}$ & $>36 \mu \mathrm{g} / \mathrm{mL}$ \\
\hline
\end{tabular}




\subsection{Vaccination}

Large efforts have been made in order to develop vaccines to control SD since Joens and co-authors [105] reported that pigs which have recovered from acute SD are protected from disease when subsequently re-exposed to $B$. hyodysenteriae, indicating that the infection can induce a protective immune response. However, attempts to date have met with limited success. Tested vaccines have included whole-cell bacterins [106-109] and orally administered attenuated strains [34,110-112]. Bacterin vaccines may provide some level of protection but they do not provide adequate cross-protective immunity against strains of different serogroups, which would require the use of autogenous or multivalent bacterins. In addition, they are relatively expensive and difficult to produce on a large scale due to the fastidious growth requirements of the spirochaete. On the other hand, attenuated or genetically modified live avirulent vaccines may show reduced colonisation and cause less immune stimulation. An alternative approach may be to generate subunit vaccines that might be delivered by the expression of recombinant $B$. hyodysenteriae proteins on a bacterial delivery vector [113]. Investigations into potential targets for such recombinant vaccines have focused on outer membrane proteins [114-117], flagelar proteins [118,119] or iron storage proteins [120], although in most occasions recombinant vaccines tested have failed to provide enough protection in pigs.

\subsection{Dietary Interventions}

As described in previous sections of this review article the pigs' diet is one of the most important factors regulating the microbial balance in the large intestine and can have a strong influence on colonisation by $B$. hyodysenteriae and on the occurrence or severity of clinical signs of SD. This suggests that control of SD may be achieved by manipulations of dietary ingredients or the use of specific dietary additives. Thus, Siba and co-workers [80] demonstrated that pigs fed a highly digestible diet based on cooked white rice and animal protein were fully protected against SD, while pigs fed diets containing lupins and/or wheat displayed clinical signs of SD. Similar results have been obtained with other diets with low contents in soluble non-starch polysaccharides (sNSP) and resistant starch (RS) [121,122], supporting the idea that microbial digestion of fermentable carbohydrates in the large intestine facilitates the occurrence of SD. However, protection against SD was also shown to be achieved through supplementation with highly fermentable carbohydrates (prebiotic diets; $[75,83]$ ).

Prebiotics are non-digestible food components which evade digestion by mammalian enzymes, in the upper regions of the gastrointestinal tract, reach the colon in an intact state and are then metabolized/fermented by beneficial members of the indigenous microbiota [123]. Selective fermentation by such microorganisms may result in a healthier composition of the gut microflora and a lower susceptibility to gastrointestinal infections. Addition of prebiotics to the diet would therefore allow the manipulation of intestinal microbiota with the final aim of improving health and well-being and preventing SD [88]. Accordingly, a high dietary concentration of inulin, whose possibly mechanisms of action have been mentioned above, has been reported to reduce the incidence of SD in pigs experimentally challenged with $B$. hyodysenteriae [86]. Nonetheless, the reduction of the risk of developing SD was only achieved with a diet supplemented with high levels of inulin $(80 \mathrm{~g} / \mathrm{kg}) \mathrm{but}$ not with lower levels, which is an expensive meal formulation. Finally, another dietary additive which has 
been reported to ameliorate $\mathrm{SD}$, through immunomodulation and reduction of colonic inflammation, is conjugated linoleic acid [124].

\subsection{Probiotics}

As previously mentioned, changes in intestinal microbiota associated with the diet are known to inhibit the development of SD [75], which suggests that supplementation of the diet with strains of beneficial bacteria (probiotics) could protect the host from B. hyodysenteriae colonisation. Interestingly, recent reports have identified a range of microorganisms with anti-Brachyspira potential [125-127]. These included lactobacilli (L. amylovorus, L. farciminis, L. rhamnosus, L. salivarius), enterococci (E. faecium), bacilli (B. subtilis), and bifidobacteria (B. thermophilum). The antagonist effects observed by these authors are not yet completely characterized and may be due to direct competition (pathogen displacement) or to the production of bacteriocins or non-specific antimicrobial substances, such as short chain fatty acids. Nevertheless, the anti-Brachyspira activity of these strains put them forward as promising probiotic feed supplements in pig production. However, challenge trials are needed to evaluate whether these bacteria exert their antagonistic effects on $\mathrm{SD}$ in vivo.

\subsection{Natural Antimicrobials}

Intense research efforts focused on the search for alternatives to antibiotics for the prevention of animal infectious diseases have been made in the last decade. Special attention has been paid to the antimicrobial activity of diverse plant and food-derived extracts and their components, which have been reported to show great in vitro inhibitory effects against major pathogenic bacteria, including various causative agents of infections in pigs [128,129]. However, little is known regarding $B$. hyodysenteriae susceptibility to this sort of antimicrobial agents. Nonetheless, an extract of citric seeds has been previously reported to inhibit B. hyodysenteriae [130], and a recent study by our research group has demonstrated the efficacy of a citrus fruit extract against this pathogenic microorganism [131]. These findings suggest that use of natural antimicrobials as feed supplements could be an attractive approach to control SD. Nevertheless, further research in clinical trials under field conditions is necessary to verify their efficacy without detrimental side effects.

\section{Conclusions and Future Prospects}

SD remains an important endemic infectious disease in many pig rearing countries, where control is limited by the lack of effective vaccines and by the emergence of $B$. hyodysenteriae strains with reduced susceptibility to common antibiotics.

Despite the great impact of SD, much remains still unknown about the virulence traits of its etiological agent and the transmission modes of the disease. The lack of molecular tools for the genetic manipulation of $B$. hyodysenteriae has hindered the identification of B. hyodysenteriae virulence factors. The performance of studies predicting the functions of different genes and macromolecules in the "genomics era" will enable the identification of new virulence factors and regulatory systems important for host colonization by B. hyodysenteriae. The publication of the first B. hyodysenteriae 
genome in 2009 has inaugurated this new era, and must serve as a starting signal for the design of ambitious molecular studies which will undoubtedly shed light on the B. hyodysenteriae conundrum.

$\mathrm{SD}$ is believed to be a multifactorial infectious disease with a complex mode of transmission. Thus, whereas $B$. hyodysenteriae has been traditionally considered a pathogen mainly transmitted by direct contact through the introduction of subclinically infected animals into a previously uninfected herd, recent findings (i.e., great survival ability of the pathogen in faeces, presence of B. hyodysenteriae and other Brachyspira species in wild boars, domestic animals, rodents, birds and insects) suggest the possibility of indirect transmission between farms. In addition, a range of underlying factors, including the production system, the farm management and the diet of pigs, are relevant for the establishment or transmission of the disease and must be considered when designing control strategies.

Control programmes of SD have been traditionally based on the use of antibiotics. However, the ban on the use of antibiotics as feed additives on farm animals and the emergence of B. hyodysenteriae strains with reduced susceptibility to one or more of the used antibiotics, has prompted researchers to search for alternatives in the treatment and prevention of SD. Innovative therapeutic strategies may be focused on the identification or development of novel antimicrobial compounds targeted at the inhibition of bacterial virulence targets, which include drugs inhibiting quorum sensing or biofilm formation. Antimicrobial compounds of natural origin (e.g., plant derived antimicrobials) and with activity on various cellular targets also represent an attractive alternative to conventional antibiotics. The acquisition through genomics-driven studies of novel knowledge on the virulence traits of $B$. hyodysenteriae and on the host immune response to the infection by this microorganism will be essential to progress on the development of a vaccine able to provide full protection against the disease. Finally, preventive measures should be also aimed to act on the underlying factors associated with the disease. This would include the control of the pig's diet, the modulation of the intestinal microbiota through the inclusion of probiotics and prebiotics on animal feed, or the improvement of farm management practices.

\section{Acknowledgments}

This work was funded by "Ministerio de Economía y Competitividad” (project AGL 2010-18804).

\section{Conflicts of interest}

The authors declare no conflict of interest.

\section{References}

1. Wills, R.W. Diarrhea in growing-finishing swine. Vet. Clin. North Am. Food Anim. Pract. 2000, 16, 135-161.

2. $\quad$ Whiting, R.A.; Doyle, L.P.; Spray, R.S. Swine dysentery. Bulletin 1937, 257, 1-15.

3. Taylor, D.J.; Alexander, T.J.L. The production of dysentery in swine by feeding cultures containing a spirochaete. Br. Vet. J. 1971, 127, 58-61. 
4. Harris, D.L.; Glock, R.D.; Christensen, C.R.; Kinyon, J.M. Inoculation of pigs with Treponema hyodysenteriae (new species) and reproduction of the disease. Vet. Med. Small Anim. Clin. 1972, 67, 61-64.

5. Hampson, D.J.; Fellstrom, C.; Thomson, J.R. Swine dysentery. In Diseases of Swine; Straw, B.E., Zimmerman, J.J., D’Allaire, S., Eds.; Blackwell Publishing Professional: Ames, IA, USA, 2006; pp. 785-805.

6. Suh, D.K.; Song, J.C. Simultaneous detection of Lawsonia intracellularis, Brachyspira hyodysenteriae and Salmonella spp. in swine intestinal specimens by multiplex polymerase chain reaction. J. Vet. Sci. 2005, 6, 231-237.

7. Fellstrom, C.; Pettersson, B.; Johansson, K.E.; Lundeheim, N.; Gunnarsson, A. Prevalence of Serpulina species in relation to diarrhea and feed medication in pig-rearing herds in Sweden. Am. J. Vet. Res. 1996, 57, 807-811.

8. Møller, K.; Jensen, T.K.; Jorsal, S.E.; Leser, T.D.; Carstensen, B. Detection of Lawsonia intracellularis, Serpulina hyodysenteriae, weakly beta-hemolytic intestinal spirochaetes, Salmonella enterica, and Escherichia coli from swine herds with and without diarrhoea among growing pigs. Vet. Microbiol. 1998, 62, 59-72.

9. Stege, H.; Jensen, T.K.; Møller, K.; Bakbo, P.; Jorsal, S.E. Prevalence of intestinal pathogens in Danish finishing pig herds. Prev. Vet. Med. 2000, 46, 279-292.

10. Carvajal, A.; de Arriba, M.L.; Rodríguez, H.; Vidal, A.B.; Duhamel, G.E.; Rubio, P. Prevalence of Brachyspira species in pigs with diarrhoea in Spain. Vet. Rec. 2006, 158, 700-701.

11. Johnston, W.T.; Dewey, C.E.; Friendship, R.M.; Smart, N.; McEwen, B.J.; Stalker, M.; de Lange, C.F.M. An investigation of the aetiology of a mild diarrhea observed in a group of grower/finisher pigs. Can. Vet. J. 2001, 42, 33-37.

12. Jacobson, M.; Gerth Lofstedt, M.; Holmgren, N.; Lundeheim, N.; Fellstrom, C. The prevalences of Brachyspira spp. and Lawsonia intracellularis in Swedish piglet producing herds and wild board population. J. Vet. Med. 2005, 52, 386-391.

13. Hampson, D.J. The Serpulina Story. In Proceedings of the 16th International Pig Veterinary Society Congress, Melbourne, Australia, 17-21 September 2000; pp. 1-5.

14. Fries, R. Conclusions and activities of previous expert groups: The scientific steering committee of the EU. J. Vet. Med. 2004, 51, 403-407.

15. Råsbäck, T.; Jansson, D.S.; Johansson, K.E.; Fellström, C. A novel enteropathogenic, strongly haemolytic spirochaete isolated from pig and mallard, provisionally designated "Brachyspira suanatina"sp. nov. Environ. Microbiol. 2007, 9, 983-991.

16. Burrough, E.R.; Strait, E.L.; Kinyon, J.M.; Bower, L.P.; Madson, D.M.; Wilberts, B.L.; Schwartz, K.J.; Frana, T.S.; Songer, J.G. Comparative virulence of clinical Brachyspira spp. isolates in inoculated pigs. J. Vet. Diagn. Invest. 2012, 24, 1025-1034.

17. Chander, Y.; Primus, A.; Oliveira, S.; Gebhart, C.J. Phenotypic and molecular characterization of a novel strongly hemolytic Brachyspira species, provisionally designated "Brachyspira hampsonii". J. Vet. Diagn. Invest. 2012, 24, 903-910. 
18. Rubin, J.E.; Costa, M.O.; Hill, J.E.; Kittrell, H.E.; Fernando, C.; Huang, Y.; O’Connor, B.; Harding, J.C.S. Reproduction of mucohaemorrhagic diarrhea and colitis indistinguishable from swine dysentery following experimental inoculation with "Brachyspira hampsonil" strain 30446. PloS One 2013, 8, e57146, doi:10.1371/journal.pone.0057146.

19. Desrosiers, R. Transmission of swine pathogens: Different means, different needs. Anim. Health Res. Rev. 2011, 12, 1-13.

20. Songer, J.G.; Glock, R.D.; Schwartz, K.J.; Harris, D.L. Isolation of Treponema hyodysenteriae from sources other than swine. J. Am. Vet. Med. Assoc. 1978, 172, 464-466.

21. Jensen, N.S.; Stanton, T.B.; Swayne, D.E. Identification of the swine pathogen Serpulina hyodysenteriae in rheas (Rhea Americana). Vet. Microbiol. 1996, 52, 259-269.

22. Boye, M.; Baloda, S.B.; Leser, T.D.; Møller, K. Survival of Brachyspira hyodysenteriae and B. pilosicoli in terrestrial microcosms. Vet. Microbiol. 2001, 81, 33-40.

23. Jansson, D.S.; Johansson, K.E.; Olofson, T.; Rasback, T.; Vagsholm, I.; Petterson, B.; Gunnarson, A.; Fellstrom, C. Brachyspira hyodysenteriae and other strongly betahemolytic and indole-positive spirochaetes isolated from mallards (Anas platyrhynchos). J. Vet. Microbiol. 2004, 53, 293-300.

24. Blunt, R.; McOrist, S. On-Farm Insect Vector Carriage of Swine Pathogens-Brachyspira and Lawsonia. In Proceedings of the 20th International Pig Veterinary Society Congress, Durban, South Africa, 22-25 June 2008; p. 291.

25. Feberwee, A.; Hampson, D.J.; Philips, N.D.; La, T.; van der Heijden, H.M.; Wellenberg, G.J.; Dwars, R.M.; Landman, W.J. Identification of Brachyspira hyodysenteriae and other Brachyspira species in chickens from laying flocks with diarrhea or reduced production or both. J. Clin. Microbiol. 2008, 46, 593-600.

26. Gallie, A.; Chesworth, M.; Blunt, R.; McOrist, S. Identification of Harmful Dipteroid Communities on Pig Farms. In Proceedings of the American Association of Swine Veterinarians, Dallas, TX, USA, 7-10 March 2009; p. 323.

27. Phillips, N.D.; La, T.; Adams, P.J.; Harland, B.L.; Fenwick, S.G.; Hampson, D.J. Detection of Brachyspira hyodysenteriae, Lawsonia intracellularis and Brachyspira pilosicoli in feral pigs. Vet. Microbiol. 2009, 134, 294-299.

28. Paster, B.J.; Dewhirst, F.E. Phylogenetic foundation of spirochaetes. J. Mol. Microb. Biotech. 2000, 2, 341-344.

29. Ter Huurne, A.A.; Gaastra, W. Swine dysentery: More unknown than known. Vet. Microbiol. 1995, 46, 347-360.

30. Bellgard, M.I.; Wanchanthuek, P.; La, T.; Ryan, K.; Moolhuijzen, P.; Albertyn, Z.; Shaban, B.; Motro, Y.; Dunn, D.S.; Schibeci, D.; et al. Genome sequence of the pathogenic intestinal spirochaete Brachyspira hyodysenteriae reveals adaptations to its lifestyle in the porcine large intestine. PLoS One 2009, 4, e4641, doi:10.1371/journal.pone.0004641.

31. Halter, M.R.; Joens, L.A. Lipooligosaccharides from Treponema hyodysenteriae and Treponema innocens. Infect. Immun. 1988, 56, 3152-3156.

32. Kennedy, M.J.; Rosnick, D.K.; Ulrich, R.G.; Yancey, R.J. Association of Treponema hyodysenteriae with porcine intestinal mucosa. J. Gen. Microbiol. 1988, 134, 1565-1576. 
33. Ter Huurne, A.A.; Muir, S.; van Houten, M.; van der Zeijst, B.A.; Gaastra, W.; Kusters, J.G. Characterization of three putative Serpulina hyodysenteriae hemolysins. Microb. Pathog. 1994, 16, 269-282.

34. Rosey, E.L.; Kennedy, M.J.; Yancey, R.J. Dual flaA1 flaB1 mutant of Serpulina hyodysenteriae expressing periplasmic flagella is severely attenuated in a murine model of swine dysentery. Infect. Immun. 1996, 64, 4154-4162.

35. Wassenaar, T.M.; Gaastra, W. Bacterial virulence: Can we draw the line? FEMS Microbiol. Lett. 2001, 201, 1-7.

36. Barth, S.; Gommel, M.; Baljer, G.; Herbst, W. Demonstration of genes encoding virulence and virulence life-style factors in Brachyspira spp. isolates from pigs. Vet. Microbiol. 2012, 155, 438-443.

37. La, T.; Phillips, N.D.; Wanchanthuek, P.; Bellgard, M.I.; O’Hara, A.J.; Hampson, D.J. Evidence that the $36 \mathrm{~kb}$ plasmid of Brachyspira hyodysenteriae contributes to virulence. Vet. Microbiol. 2011, 153, 150-155.

38. Olson, L.D. Clinical and pathological observations on the experimental passage of swine dysentery. Can. J. Comp. Med. 1974, 38, 7-13.

39. Moreng, N.T.; Quarles, C.L.; Fagerberg, D.J.; Moeller, D.J. Pathogenesis and lesions of swine dysentery induced by artificial methods in early weaned pigs. Vet. Med. Small Anim. Clin. 1980, 75, 1841-1844.

40. Savage, D.C. Colonization by and survival of pathogenic bacteria on intestinal mucosal surfaces. In Adsorption of Microorganisms to Surfaces; Bitton, B., Marshall, K.C., Eds.; Wiley: New York, NY, USA, 1980; pp. 175-206.

41. Kinyon, J.M.; Harris, D.L.; Glock, R.D. Isolation of Treponema hyodysenteriae from Experimentally Infected Pigs at Various Intervals Post-Inoculation. In Proceedings of the 6th International Pig Veterinary Society Congress, Copenhagen, Denmark, 30 June-3 July 1980; p. 232.

42. Hampson, D.J.; Cutler, R.; Lee, B.J. Virulent Serpulina hyodysenteriae from a pig in a herd free of clinical swine dysentery. Vet. Rec. 1992, 131, 318-319.

43. Chia, S.P.; Taylor, D.J. Factors affecting the survvial of Treponema hyodysenteriae in dysenteric pig faeces. Vet. Rec. 1978, 103, 68-70.

44. Harris, D.L.; Hampson, D.J.; Glock, R.D. Diseases of Swine; Straw, B.E., D’Allaire, S.D., Mengelling, W.D., Taylor, D.J., Eds.; Iowa State University Press: Ames, IA, USA, 1999; pp. 579-600.

45. Songer, J.G.; Harris, D.L. Transmission of swine dysentery by carrier pigs. Am. J. Vet. Res. 1978, 39, 913-916.

46. Hidalgo, A.; Osorio, J.; Papaterra, G.J.; Llanos, A.; Marca, J.; Ferro, A.; Hernandez-Caravaca, I.; Carvajal, A.; Rubio, P. Control of Swine Dysentery with an Innactivated Autovaccine against Brachyspira hyodysenteriae in a Multiplier Herd. In Proceedings of the 20th International Pig Veterinary Society Congress, Durban, South Africa, 22-25 June 2008; p. 242. 
47. Osorio, J.; Hidalgo, A.; Papaterra, G.J.; Llanos, A.; Marca, J.; Ferro, A.; Hernandez-Dávila, C.; Carvajal, A.; Rubio, P. Control of Swine Dysentery with An Autogenous Bacterin of Brachyspira hyodysenteriae in Iberian Pigs. In Proceedings of the 20th International Pig Veterinary Society Congress, Durban, South Africa, 22-25 June 2008; p. 249.

48. Kanora, A.; de Groote, S.; Fockedey, M.; Velesova, S.; Karanikolova, M. Brachyspira Causing Enteric Disorder in Young Fattening Pigs Coming from Same Reproduction Pyramid. In Proceedings of the 20th International Pig Veterinary Society Congress, Durban, South Africa, 22-25 June 2008; p. 249.

49. Robertson, I.D.; Mhoma, J.R.; Hampson, D.J. Risk factors associated with the occurrence of swine dysentery in Western Australia: Results of a postal survey. Aust. Vet. J. 1992, 69, 92-101.

50. Fellström, C; Rasbäck, T. How to Handle Swine Dysentery-the Swedish Approach. In Proceedings of the 5th Spiroconference, León, Spain, 8-10 June 2009; pp. 41-43.

51. Bano, L.; Merialdi, G.; Bonilauri, P.; Dall'Anese, G.; Capello, K.; Comin, D.; Cattoli, G.; Sanguinetti, V.; Hampson, D.J.; Agnoletti, F. Prevalence, disease associations and risk factors for colonization with intestinal spirochaetes (Brachyspira spp.) in flocks of laying hens in north-eastern Italy. Avian Pathol. 2008, 37, 281-286.

52. McOrist, S.; Bennett, C. Eradication of Swine Dysentery on Large-Scale Breeder Farms by Partial Depopulation/Medication. In Proceedings of the 20th International Pig Veterinary Society Congress, Durban, South Africa, 22-25 June 2008; p. 319.

53. Phillips, N.D.; La, T.; Hampson, D.J. Survival of intestinal spirochaete strains from chickens in the presence of disinfectants and in faeces held at different temperatures. Avian Pathol. 2003, 32, 639-643.

54. Pico, L.; Szancer, J.; Pique, J.; Domeneque, A.; Rodriguez-Sierra, E.; Vidal, A. Swine Dysentery Eradication Programme in a Large Farm with Three Site Production by Strategic Management and Medication. In Proceedings of the 20th International Pig Veterinary Society Congress, Durban, South Africa, 22-25 June 2008; p. 131.

55. Rajska, M.; Kempa, W.; Wilczynski, K. Experiences with Control Programme of Swine Dysentery in A Typical POLISH Pig Unit. In Proceedings of the 20th International Pig Veterinary Society Congress; Durban, South Africa, 22-25 June 2008; p. 250.

56. Hampson, D.J.; Combs, B.G.; Harders, S.J.; Connaughton, I.D.; Fahy, V.A. Isolation of Treponema hyodysenteriae from a wild rat living on a piggery. Aust. Vet. J. 1991, 68, 308.

57. Backhans, A.; Johansson, K.E.; Fellström, C. Spirochaetes Isolated from Wild Rodents. In Proceedings of the 5th Spiroconference, León, Spain, 8-10 June 2009; pp. 58-59.

58. Trott, D.J.; Atyeo, R.F.; Lee, J.I.; Swayne, D.A.; Stoutenburg, J.W.; Hampson, D.J. Genetic relatedness amongst intestinal spirochaetes isolated from rats and birds. Lett. Appl. Microbiol. 1996, 23, 431-436.

59. Fellstrom, C.; Holmgren, N. Mice as reservoirs for swine dysentery in a fattening herd. Svensk Veterinartid. 2005, 57, 19-21.

60. Backhans, A.; Jansson, D.S.; Aspán, A.; Fellström, C. Typing of Brachyspira spp. from rodents, pigs and chickens on Swedish farms. Vet. Microbiol. 2011, 153, 156-162.

61. Jensen, N.S.; Stanton, T.B.; Swayne, D.E. Identification of the swine pathogen Serpulina hyodysenteriae in rheas (Rhea americana). Vet. Microbiol. 1996, 52, 259-269. 
62. Swayne, D.E.; McLaren, A.J. Avian intestinal spirochaetes and avian intestinal spirochaetosis. In Intestinal Spirochaetes in Domestic Animals and Humans; Hampson, D.J., Stanton, T.B., Eds.; CAB International: New York, NY, USA, 1997; pp. 267-300.

63. Oxberry, S.L.; Trott, D.J.; Hampson, D.J. Serpulina pilosicoli, waterbirds and water: Potential sources of infection for humans and other animals. Epidemiol. Infect. 1998, 121, 219-225.

64. Duhamel, G.E. Comparative pathology and pathogenesis of naturally acquired and experimentally induced colonic spirochetosis. Anim. Health Res. Rev. 2001, 2, 3-17.

65. Jansson, D.S.; Rasback, T.; Fellstrom, C.; Feinstein, R. Experimental challenge of mallards (Anas platyrhynchos) with Brachyspira hyodysenteriae and "Brachyspira suanatina" isolated from pigs and mallards. J. Comp. Pathol. 2009, 141, 211-222.

66. Jansson, D.S.; Persson, M.; Zimmerman, U.; Johansson, K.E. Phenotypic and genetic diversity among intestinal spirochaetes (genus Brachyspira) in free-living wild mallards (Anas platyrhynchos) sampled in southern Sweden. Syst. Appl. Microbiol. 2011, 34, 566-575.

67. Sagartz, J.E.; Swayne, D.E.; Eaton, K.A.; Hayes, J.R.; Amass, K.D.; Wack, R.; Kramer, L. Necrotizing typhlocolitis associated with a spirochaete in rheas (Rhea americana). Avian Dis. 1992, 36, 282-289.

68. Buckles, E.L. Inoculation of Neonatal Common Rheas (Rhea americana) and Mallard Ducklings (Anas platyrhynchos) with Three Bacterial Species Associated with Necrotizing Typhlitis. M.Sc. Thesis, Ohio State University, Columbus, OH, USA, 1996; pp. 43-66.

69. Buckles, E.L.; Eaton, K.A.; Swayne, D.E. Cases of spirochaete associated necrotizing typhlitis in captive common rheas (Rhea americana). Avian Dis. 1997, 41, 144-148.

70. Stanton, T.B.; Jensen, N.S.; Bosworth, B.T.; Kunkle, R.A. Evaluation of the Virulence of Rhea $S$. hyodysenteriae Strains for Swine. Brachyspira hyodysenteriae in Mallards. In Proceedings of the 1st International Virtual Conference on Infectious Diseases of Animals, National Animal Disease Center, Ames, IA, USA, 20 April-2 May 1997.

71. Blunt, R.; Hancox, L.; Mellits, K.; McOrist, S. Likely Carriage of Brachyspira hyodysenteriae in Cockroaches and Flies on Pig Farms. In Proceedings of the 21st International Pig Veterinary Society Congress, Vancouver, BC, Canada, 18-21 July 2010; p. 93.

72. Blunt, R.; McOrist, S. The Potential Transmission of Swine Dysentery by Cockroach Vectors. In Proceedings of the 5th Spiroconference, León, Spain, 8-10 June 2009; p. 14.

73. Fellström, C.; Jacobsson, M. Screening for Brachyspira spp. and Lawsonia intracellularis in European Wild Pigs. In Proceedings of the 17th International Pig Veterinary Society Congress, Ames, IA, USA, 2-5 June 2002; p. 367.

74. Songer, J.G.; Glock, R.D.; Schwartz, K.J.; Harris, D.L. Isolation of Treponema hyodysenteriae from sources other than swine. J. Am. Vet. Med. Assoc. 1978, 172, 464-466.

75. Huisman, J.; Jansman, A.J.M. Dietary effects and some analytical aspects of antinutritional factors in pea (Pisum sativum), common beans (Phaseolus vulgaris) and soyabeans (Glycine max L.) in monogastric farm animals. A literature review. Nutr. Abstr. Rev. 1991, 61, 901-921.

76. Dréau, D.; Lallés, J.P.; Philouze-Romé, V.; Toullec, R.; Salmon, H. Local and systemic immune responses to soybean protein ingestion in early-weaned pigs. J. Anim. Sci. 1994, 72, 2090-2098. 
77. Whipp, S.C.; Robinson, I.M.; Harris, D.L.; Glock, R.D.; Matthews, P.J.; Alexander, T.J. Pathogenic synergism between Treponema hyodysenteriae and other selected anaerobes in gnotobiotic pigs. Infect. Immun. 1979, 26, 1042-1047.

78. Dréau, D.; Lallés, J.P.; Toullec, R.; Salmon, H. B and T lymphocytes are enhanced in the gut of piglets fed heat-treated soyabean proteins. Vet. Immunol. Immunopathol. 1995, 47, 69-79.

79. Neef, N.A.; McOrist, S.; Lysons, R.J.; Bland, A.P.; Miller, B.G. Development of large intestinal attaching and effacing lesions in pigs in association with the feeding of a particular diet. Infect. Immun. 1994, 62, 4325-4332.

80. Siba, P.M.; Pethick, D.W.; Hampson, D.J. Pigs experimentally infected with Serpulina hyodysenteriae can be protected from developing swine dysentery by feeding them a highly digestible diet. Epidemiol. Infect. 1996, 116, 207-216.

81. Durmic, Z.; Pethick, D.; Mullan, B.; Schulze, H.; Accioly, J.; Hampson, D. Extrusion of wheat or sorghum and/or addition of exogenous enzymes to pig diets influences the large intestinal microbiota but does not prevent development of swine dysentery following experimental challenge. J. Appl. Microbiol. 2000, 89, 678-686.

82. Lindecrona, R.H.; Jensen, T.K.; Jensen, B.B.; Leser, T.D.; Jiufeng, W.; Møller, K. The influence of diet on the development of swine dysentery upon experimental infection. Anim. Sci. 2003, 76, $81-87$.

83. Thomsen, L.E.; Bach Knudsen, K.E.; Jensen, T.K.; Christensen, A.S.; Møller, K.; Roepstorff, A. The effect of fermentable carbohydrates on experimental swine dysentery and whip worm infections in pigs. Vet. Microbiol. 2007, 119, 152-163.

84. Hansen, C.F.; Phillips, N.D.; La, T.; Hernández, A.; Mansfield, J.; Kim, J.C.; Mullan, B.P.; Hampson, D.J.; Pluske, J.R. Diets containing inulin but not lupins help to prevent swine dysentery in experimentally challenged pigs. J. Anim. Sci. 2010, 88, 3327-3336.

85. Roberfroid, M.B.; van Loo, J.A.E.; Gibson, G.R. The bifidogenic nature of chicory inulin and its hydrolysis products. J. Nutr. 1998, 128, 11-19.

86. Hansen, C.; Hernández, A.; Mansfield, J.; Hidalgo, A.; La, T.; Phillips, N.; Hampson, D.; Pluske, J. A high dietary concentration of inulin is necessary to reduce the incidence of swine dysentery in pigs experimentally challenged with Brachyspira hyodysenteriae. Br. J. Nutr. 2011, 106, 1506-1513.

87. Cummings, J.H.; Macfarlane, G.T. The control and consequences of bacterial fermentation in the human colon. J. Appl. Bacteriol. 1991, 70, 443-459.

88. Mølbak, L.; Thomsen, L.E.; Jensen, T.K.; Bach Knudsen, K.E.; Boye, M. Increased amount of Bifidobacterium thermacidophilum and Megasphaera elsdenii in the colonic microbiota of pigs fed a swine dysentery preventive diet containing chicory roots and sweet lupine. J. Appl. Microbiol. 2007, 103, 1853-1867.

89. Kowalski, C.; Zarí, R.; Rolinski, Z. Pleuromutilin derivatives and their usage in veterinary treatment. Med. Weter. 2004, 60, 22-26.

90. Molnar, L. Sensitivity of strains of Serpulina hyodysenteriae isolated in Hungary to chemotherapeutic drugs. Vet. Rec. 1996, 138, 158-160.

91. Gresham, A.C.; Hunt, B.W.; Dalziel, R.W. Treatment of swine dysentery-Problems of antibiotic resistance and concurrent salmonellosis. Vet. Rec. 1998, 143, 619. 
92. Karlsson, M.; Gunnarsson, A.; Franklin, A. Susceptibility to pleuromutilins in Brachyspira (Serpulina) hyodysenteriae. Anim. Health Res. Rev. 2001, 2, 59-65.

93. Karlsson, M.; Fellstrom, C.; Gunnarsson, A.; Landen, A.; Franklin, A. Antimicrobial susceptibility testing of porcine Brachyspira (Serpulina) species isolates. J. Clin. Microbiol. 2003, 41, 2596-2604.

94. Lobova, D.; Smola, J.; Cizek, A. Decreased susceptibility to tiamulin and valnemulin among Czech isolates of Brachyspira hyodysenteriae. J. Med. Microbiol. 2004, 53, 287-291.

95. Rohde, J.; Kessler, M.; Baums, C.G.; Amtsberg, G. Comparison of methods for antimicrobial susceptibility testing and MIC values for pleuromutilin drugs for Brachyspira hyodysenteriae isolated in Germany. Vet. Microbiol. 2004, 102, 25-32.

96. Hidalgo, A.; Carvajal, A.; García-Feliz, C.; Osorio, J.; Rubio, P. Antimicrobial susceptibility testing of Spanish field isolates of Brachyspira hyodysenteriae. Res. Vet. Sci. 2009, 87, 7-12.

97. Hidalgo, A.; Carvajal, A.; Vester, B.; Pringle, M.; Naharro, G.; Rubio, P. Trends towards lower antimicrobial susceptibility and characterization of acquired resistance among clinical isolates of Brachyspira hyodysenteriae in Spain. Antimicrob. Agents Ch. 2011, 55, 3330-3337.

98. Ohya, T.; Sueyoshi, M. In vitro antimicrobial susceptibility of Brachyspira hyodysenteriae strains isolated in Japan from 1985 to 2009. J. Vet. Med. Sci. 2010, 72, 1651-1653.

99. Karlsson, M.; Fellstrom, C.; Heldtander, M.U.; Johansson, K.E.; Franklin, A. Genetic basis of macrolide and lincosamide resistance in Brachyspira (Serpulina) hyodysenteriae. FEMS Microbiol. Lett. 1999, 172, 255-260.

100. Karlsson, M.; Fellstrom, C.; Johansson, K.E.; Franklin, A. Antimicrobial resistance in Brachyspira pilosicoli with special reference to point mutations in the $23 \mathrm{~S}$ rRNA gene associated with macrolide and lincosamide resistance. Microb. Drug Resist. 2004, 10, 204-208.

101. Pringle, M.; Poehlsgaard, J.; Vester, B.; Long, K.S. Mutations in ribosomal protein L3 and 23S ribosomal RNA at the peptidyl transferase centre are associated with reduced susceptibility to tiamulin in Brachyspira spp. isolates. Mol. Microbiol. 2004, 54, 1295-1306.

102. Pringle, M.; Landén, A.; Unnerstad, H.E.; Molander, B.; Bengtsson, B. Antimicrobial susceptibility of porcine Brachyspira hyodysenteriae and Brachyspira pilosicoli isolated in Sweden between 1990 and 2010. Acta Vet. Scand. 2012, 54, 54, doi:10.1186/1751-0147-54-54.

103. Rønne, H.; Szancer, J. In Vitro Susceptibility of Danish Field Isolates of Treponema hyodysenteriae to Chemotherapeutics in Swine Dysentery (SD) Therapy. Interpretation of MICs Results Based on Pharmacokinetic Properties of the Antibacterial Agents. In Proceedings of the 11th International Pig veterinary Society Congress, Lausanne, Switerzland, 1-5 July 1990; p. 126.

104. Burch, D.G.S. Pharmacokinetic, pharmacodynamic and clinical correlations relating to the therapy of colonic infections in the pig and breakpoints determinations. Pig J. 2005, 56, 8-24.

105. Joens, L.A.; Harris, D.L.; Baum, D.H. Immunity to swine dysentery in recovered pigs. Am. J. Vet. Res. 1979, 40, 1352-1354.

106. Fernie, D.S.; Ripley, P.H.; Walker, P.D. Swine dysentery: Protection against experimental challenge following single dose parenteral immunisation with inactivated Treponema hyodysenteriae. Res. Vet. Sci. 1983, 35, 217-221. 
107. Parizek, R.; Stewart, R.; Brown, K.; Blevins, D. Protection against swine dysentery with an inactivated Treponema hyodysentariae bacterin. Vet. Med. 1985, 80, 80-86.

108. Diego, R.; Lanza, I.; Carvajal, A.; Rubio, P.; Carmenes, P. Serpulina hyodysenteriae challenge of fattening pigs vaccinated with an adjuvanted bivalent bacterin against swine dysentery. Vaccine 1995, 13, 663-667.

109. Waters, W.R.; Sacco, R.E.; Dorn, A.D.; Hontecillas, R.; Zuckermann, F.A.; Wannemuehler, M.J. Systemic and mucosal immune responses of pigs to parenteral immunization with a pepsin-digested Serpulina hyodysenteriae bacterin. Vet. Immunol. Immunopathol. 1999, 69, 75-87.

110. Hudson, M.J.; Alexander, T.L.J.; Lysons, R.J.; Wellstead, P.D. Swine dysentery: Failure of an attenuated strain of spirochaete, given orally, to protect pigs against subsequent challenge. Br. Vet. J. 1974, 130, 37-40.

111. Lysons, R.; Burrows, M.R.; Jones, P.W.; Collins, P. Swine dysentry, a new and effective vaccine. Proc. Int. Pig Vet. Soc. 1987, 18, 87-91.

112. Hyatt, D.R.; Ter Huurne, A.A.; van der Zeijst, B.A.; Joens, L.A. Reduced virulence of Serpulina hyodysenteriae hemolysin-negative mutants in pigs and their potential to protect pigs against challenge with a virulent strain. Infect. Immun. 1994, 62, 2244-2248.

113. Song, Y.; La, T.; Phillips, N.D.; Bellgard, M.I.; Hampson, D.J. A reverse vaccinology approach to swine dysentery vaccine development. Vet. Microbiol. 2009, 137, 111-119.

114. Joens, L.A.; Marquez, M.R.; Halter, M. Comparison of outer-membrane fractions of Serpulina (Treponema) hyodysenteriae. Vet. Microbiol. 1993, 35, 119-132.

115. La, T.; Phillips, N.D.; Reichel, M.P.; Hampson, D.J. Protection of pigs from swine dysentery by vaccination with recombinant $\mathrm{BmpB}$, a $29.7 \mathrm{kDa}$ outer-membrane lipoprotein of Brachyspira hyodysenteriae. Vet. Microbiol. 2004, 102, 97-109.

116. Witchell, T.D.; Coutts, S.A.J.; Bulach, D.M.; Adler, B. Differential expression of the Bhmp39 major outer membrane proteins of Brachyspira hyodysenteriae. Infect. Immun. 2006, 74, 3271-3276.

117. Holden, J.; Coloe, P.J.; Smooker, P.M. An evaluation of the immunogenicity and protective responses to Brachyspira hyodysenteriae recombinant $\mathrm{SmpB}$ vaccination. Vet. Microbiol. 2008, 128, 354-363.

118. Boyden, D.A.; Albert, F.G.; Robinson, C.S. Cloning and characterization of Treponema hyodysenteriae antigens and protection in a CF-1 mouse model by immunization with a cloned endoflagellar antigen. Infect. Immun. 1989, 57, 3808-3815.

119. Gabe, J.D.; Chang, R.J.; Slomiany, R.; Andrews, W.H.; McCaman, M.T. Isolation of extracytoplasmic proteins from Serpulina hyodysenteriae B204 and molecular cloning of the flaB1 gene encoding a 38-kilodalton flagellar protein. Infect. Immun. 1995, 63, 142-148.

120. Davis, A.J.; Smith, S.C.; Moore, R.J. The Brachyspira hyodysenteriae ftnA gene: DNA vaccination and real-time PCR quantification of bacteria in a mouse model of disease. Curr. Microbiol. 2005, 50, 285-291.

121. Pluske, J.; Durmic, Z.; Pethick, D.; Mullan, B.; Hampson, D. Confirmation of the role of rapidly fermentable carbohydrates in the expression of swine dysentery in pigs after experimental infection. J. Nutr. 1998, 128, 1737-1744. 
122. Durmic, Z.; Pethick, D.W.; Mullan, B.P.; Accioly, J.M.; Schulze, H.; Hampson, D.J. Evaluation of large intestinal parameters associated with dietary treatments designed to reduce the occurrence of swine dysentery. Br. J. Nutr. 2002, 88, 159-169.

123. Gibson, G.R.; Roberfroid, M.B. Dietary modulation of the human colonic microbiota: Introducing the concept of prebiotics. J. Nutr. 1995, 125, 1401-1412.

124. Hontecillas, R.; Wannemeulher, M.J.; Zimmerman, D.R.; Hutto, D.L.; Wilson, J.H.; Ahn, D.U.; Bassaganya-Riera, J. Nutritional regulation of porcine bacterial-induced colitis by conjugated linoleic acid. J. Nutr. 2002, 132, 2019-2027.

125. Bernardeau, M.; Gueguen, M.; Smith, D.G.E.; Corona-Barrera, E.; Vernoux, J.P. In vitro antagonistic activities of Lactobacillus spp. against Brachyspira hyodysenteriae and Brachyspira pilosicoli. Vet. Microbiol. 2009, 138, 184-190.

126. Klose, V.; Bayer, K.; Bruckbeck, R.; Schatzmayr, G.; Loibner, A.P. In vitro antagonistic activities of animal intestinal strains against swine-associated pathogens. Vet. Microbiol. 2010, 144, 515-521.

127. Klose, V.; Bruckbeck, R.; Henikl, S.; Schatzmayr, G.; Loibner, A.P. Identification and antimicrobial susceptibility of porcine bacteria that inhibit the growth of Brachyspira hyodysenteriae in vitro. J. Appl. Microbiol. 2010, 108, 1271-1280.

128. Lyoo, Y.; Park, D.; Lee, S.; Choi, Y.; Jung, J.; Jun, T.; Ahm, H.; Lee, Ch.; Lym, Y. Antibacterial compound against Pasteurella multocida and Actinobacillus pleuropneumoniae causing porcine pneumonia. J. Microbiol. Biotech. 2001, 11, 350-353.

129. Becker, P.M.; van Wikselaar, P.G.; Mul, M.F.; Pol, A.; Engel, B.; Wijdenes, J.W.; van der Peet-Schwering, C.M.; Wisselink, H.J.; Stockhofe-Zurwieden, N. Actinobacillus pleuropneumoniae is impaired by the garlic volatile allyl methyl sulphide (AMS) in vitro and in-feed garlic alleviates pleuropneumonia in a pig model. Vet. Microbiol. 2012, 154, 316-324.

130. Lobova, D.; Cizek, A. Bactericidal efficacy of two disinfectants against Brachyspira hyodysenteriae and one feed supplement against B. hyodysenteriae and B. pilosicoli. Vet. Med. Czech 2004, 49, $156-160$.

131. Alvarez-Ordóñez, A.; Carvajal, A.; Arguello, H.; Martínez-Lobo, F.J.; Naharro, G.; Rubio, P. Antibacterial activity and mode of action of a commercial citrus fruit extract. J. Appl. Microbiol. 2013, doi:10.1111/jam.12216.

(C) 2013 by the authors; licensee MDPI, Basel, Switzerland. This article is an open access article distributed under the terms and conditions of the Creative Commons Attribution license (http://creativecommons.org/licenses/by/3.0/). 